\title{
Failure Behaviour of Concrete Prisms Strengthened by Various Bond Widths of Carbon Fibre Reinforced Polymer (CFRP)
}

\author{
Syed Mohamad Syahir Syed Mazlan ${ }^{1,{ }^{*}, \text { Siti Radziah Abdullah }}{ }^{1}$, Shahiron Shahidan ${ }^{1}$, and \\ Siti Rahimah Mohd Noor ${ }^{1}$ \\ ${ }^{1}$ Jamilus Research Center, Universiti Tun Hussein Onn Malaysia, 86400 Parit Raja, Johor, Malaysia
}

\begin{abstract}
The use of fibre reinforced polymers (FRP) for external strengthening of concrete structures in various forms such as laminates and sheets has become moderately common. FRP is more effective as it provides a better solution in terms of properties and application. The effectiveness of the FRP strengthening system lies in the bond between concrete and FRP which is affected by various factors such as bond length of FRP, bond width, resin hardening and surface preparation. In certain cases, bond width is a major factor which ensures that the structure can be strengthened properly. This paper focuses mainly on the failure behaviour of concrete prisms strengthened by various bond width ratios of carbon Fibre Reinforced Polymer (CFRP) which are $20 \mathrm{~mm}(0.27), 40 \mathrm{~mm}(0.53)$, $60 \mathrm{~mm}(0.8)$ and $75 \mathrm{~mm}(1)$ respectively. A total of fifteen strengthened prisms measuring $75 \mathrm{~mm} \times 75 \mathrm{~mm} \times 350 \mathrm{~mm}$ were cast for a three-point load test. Twelve strengthened prism specimens were externally strengthened with CFRP and three specimens were designated as control. The findings show that a greater width ratio of CFRP will strengthen concrete prisms greatly and will result in different types of failure modes.
\end{abstract}

\section{Introduction}

Nowadays, the application of Fiber Reinforced Polymer (FRP) material is increasing in the construction sector especially in strengthening deficient concrete structures [1]. These materials are lightweight, non-corrosive, and exhibit higher tensile strength [2, 3]. FRP can be used to rehabilitate or restore the strength of deteriorated structural members, retrofit or strengthen sound structural members to resist increased loads due to change in use of the structure, or address design or construction errors on a structure [4-6].

Certain advantages of FRP composites including high tensile strength, light weight and ease of application have led engineers all over the world to utilize FRP as an easy-to-use alternative compared to conventional materials for strengthening reinforced concrete structures [7]. Almost all flexural or shear strengthening techniques with FRP rely on the bonding of the composite onto the concrete substrate [8]. The effectiveness of the FRP strengthening system mainly depends on the effective length due to the bond of FRP on the

* Corresponding author: syedmsyahir@gmail.com 
effective zone [9]. However, temperature sensitivity, concrete quality, surface preparation, width of FRP and bond length are some of the factors that affect the ultimate strength of the specimen between concrete and FRP [10]. In previous studies, it was highlighted that the width ratio of CFRP plays an important role in influencing the debonding failure of CFRP [12-15] The greater width ratio of an FRP plate will develop higher interfacial bond strength of FRP to concrete and a smaller global slip of FRP to concrete [15]. Thus, a greater width ratio of FRP plate will give the greater slope of elastic deformation of the global slip but a lower ductility of FRP to concrete. When the width ratio value is close to 1, it will give the best FRP performance. Other than that, every width ratio will form different types of failure modes as shown in Fig. 1 [14]. Therefore, from previous studies, the result of concrete strengthened with FRP will produce different results based on the types of preparation such as different types of FRP, plies of FRP, bond length of FRP and width ratio of FRP. This study focuses on the effect of different width ratios of CFRP to enhance concrete strength and types of failure modes produced.

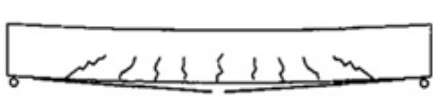

(a)

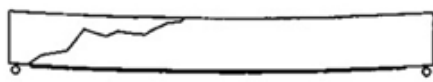

(c)

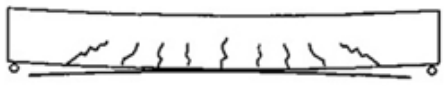

(e)

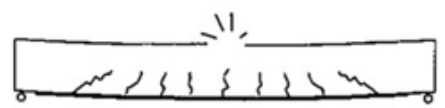

(b)

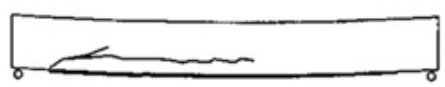

(d)

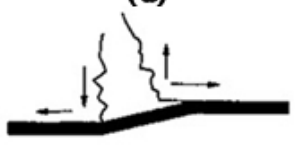

(f)

Fig. 1. Failure mode in FRP as a strengthened prism: (a) steel yield and FRP rupture, (b) concrete compression failure, (c) shear failure, (f) debond of layer along rebar, (g) delamination of FRP plate, (h) peeling due to shear cracks.

\section{Experimental programs}

A total of fifteen (15) strengthened prisms measuring $75 \mathrm{~mm}$ x $75 \mathrm{~mm} \times 350 \mathrm{~mm}$ were cast for a three-point load test. Twelve (12) strengthened prisms specimens were externally strengthened with CFRP and three (3) specimens were designated as control or nonstrengthened prisms.

\subsection{CFRP strengthening}

Concrete prisms of grade 30 were cured for 28 days. In this study, the type of FRP used was uniaxial CFRP or SIKA WRAP -231C. The mechanical properties of CFRP for tensile strength, modulus of elasticity and tensile strain are $4900 \mathrm{MPa}, 230 \mathrm{GPa}$ and $1.7 \%$ respectively. The CFRP was attached to the concrete prism as illustrated in Fig. 2 and the prism surface was grinded to obtain a rough surface to ensure perfect bonding and a clean condition [16]. Then the CFRP was attached to the concrete prisms and cured for 7 days at room temperature. 


\subsection{Specimen characteristics and strengthening conformation}

The size of strengthened prisms was $350 \mathrm{~mm}$ long, $75 \mathrm{~mm}$ wide and $75 \mathrm{~mm}$ high. The width ratios of the CFRP attached was $20 \mathrm{~mm}(0.27), 40 \mathrm{~mm}(0.53), 60 \mathrm{~mm}(0.8)$ and $75 \mathrm{~mm}$ (1) respectively. The details on the dimensions and CFRP attachments are illustrated in Fig. 2.
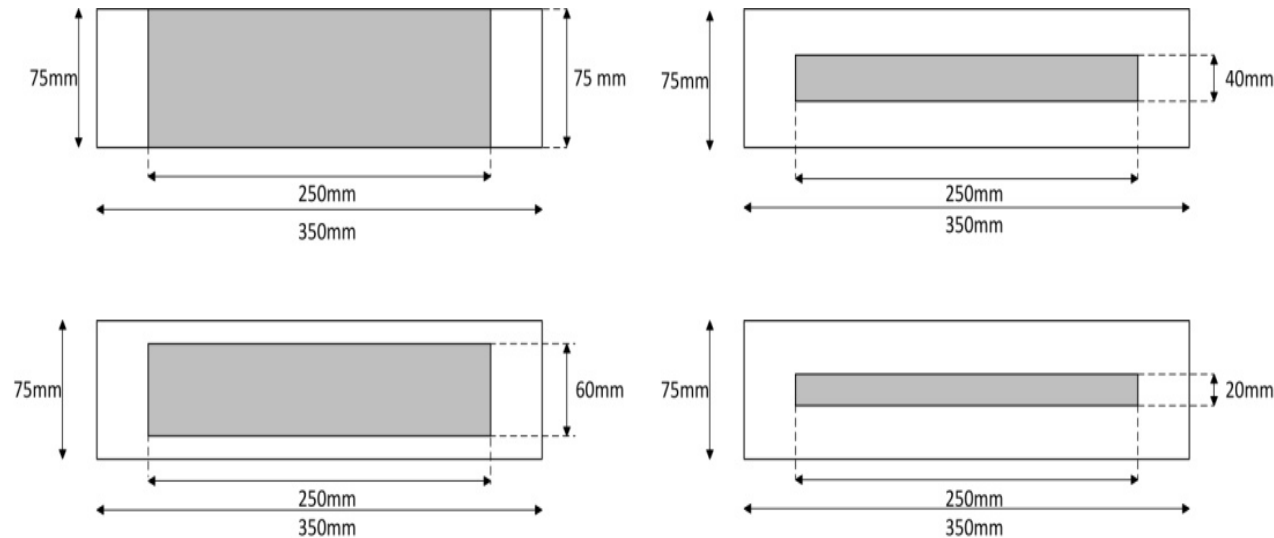

Fig. 2. Bottom view details for the dimensions of CFRP attachment to the strengthened prisms.

\subsection{Test Setup}

A three-point load test was conducted on strengthened prism specimens to determine the maximum force applied, deflection, and failure behaviour of strengthened prisms after the specimens failed. A test instrumentation setup is presented in Fig. 3. The strengthened prisms specimens were placed onto two-pin supports located at both ends of the specimen. A linear variable displacement transducer (LVDT) was connected to a computer in order to determine the deflection of the strengthened prisms.

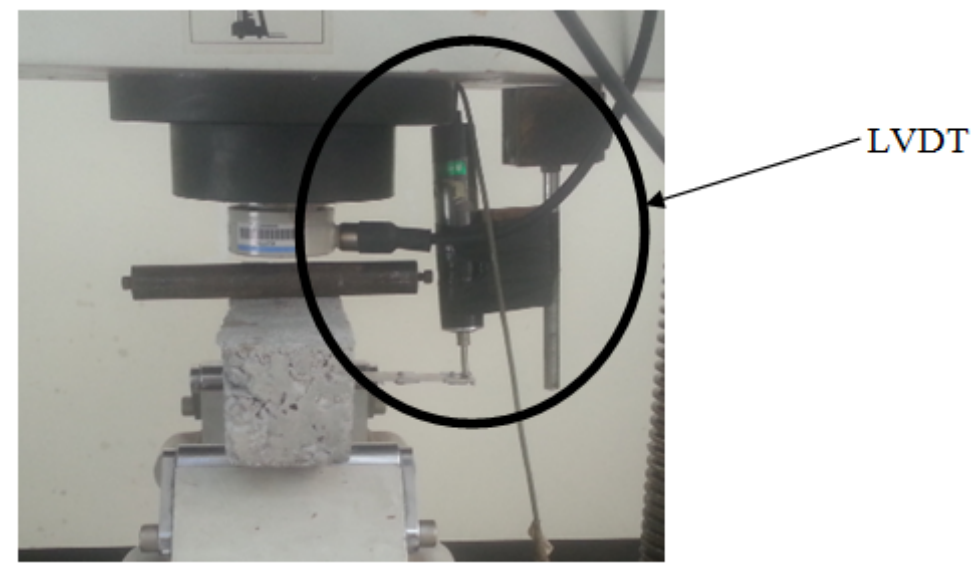

Fig. 3. Strengthened prisms were placed on two-pin supports with a linear variable displacement transducer (LVDT) installed at the centre of the strengthened prisms. 


\section{Results and analysis}

\subsection{Effect of width ratio on concrete}

The results from the three point load test comprising of ultimate load, average ultimate load and percentage of increase for all tested prisms are presented in Table 1. For control specimens without CFRP, the average ultimate load is $13.06 \mathrm{kN}$. When the CFRP was attached to the concrete prism, it was found that the ultimate load of the concrete increased as the CFRP width ratio increased. For CFRP with a width ratio of 0.27 , the percentage of the ultimate load increased by $47.39 \%$ compared to the specimen without CFRP. For the specimen attached to CFRP with a width ratio of 0.53 , the average ultimate load is $24.6 \mathrm{kN}$ which is $89.05 \%$ higher than the specimen without CFRP. The trend of ultimate load increases when the width ratio increases and this is graphically presented in Fig. 4. The specimen attached to CFRP with a width ratio of 1 attained the highest average ultimate load of $37.5 \mathrm{kN}$ with an increased percentage of $187.23 \%$ compared to the specimen without CFRP.

Table 1. Tabulated data of average three point load test

\begin{tabular}{|c|c|c|c|c|}
\hline \multirow{2}{*}{$\begin{array}{l}\text { Width } \\
\text { Ratio } \\
W_{p} / W_{c}\end{array}$} & \multirow[b]{2}{*}{ Specimen } & \multicolumn{3}{|c|}{ Three point load test } \\
\hline & & $\begin{array}{l}\text { Ultimate } \\
\text { load }(k N)\end{array}$ & $\begin{array}{l}\text { Average } \\
\text { ultimate } \\
\text { load }(k N)\end{array}$ & $\begin{array}{l}\text { Percentage of } \\
\text { increase }(\%)\end{array}$ \\
\hline \multirow{3}{*}{0} & \multirow{3}{*}{ W0 } & 13.64 & \multirow{3}{*}{13.06} & \multirow{3}{*}{0} \\
\hline & & 11.00 & & \\
\hline & & 14.52 & & \\
\hline \multirow{2}{*}{0.27} & \multirow{2}{*}{ W20 } & 18.33 & \multirow{2}{*}{19.25} & \multirow{2}{*}{47.39} \\
\hline & & 20.61 & & \\
\hline \multirow{2}{*}{0.53} & \multirow{2}{*}{ W40 } & 24.81 & \multirow{2}{*}{24.6} & \multirow{2}{*}{89.05} \\
\hline & & 24.57 & & \\
\hline \multirow{3}{*}{0.80} & \multirow{3}{*}{ W60 } & 34.89 & \multirow{3}{*}{33.38} & \multirow{3}{*}{155.67} \\
\hline & & 32.37 & & \\
\hline & & 32.89 & & \\
\hline \multirow{3}{*}{1.00} & \multirow{3}{*}{ W75 } & 36.89 & \multirow{3}{*}{37.50} & \multirow{3}{*}{187.23} \\
\hline & & 37.73 & & \\
\hline & & 37.89 & & \\
\hline
\end{tabular}

From the failure load graph, it can be observed that when the width of ratio increased, the load also increased as shown in figure 4 . The failure load for each width ratio resulted in different modes of failure as discussed in [16]. One control prism and four CFRP strengthened concrete prisms experienced different noticeable failure loads respectively. Every prism shows an increase in load between $4 \mathrm{kN}$ to $8 \mathrm{kN}$ for every width ratio. As the load gradually increased, the prism underwent minor FRP rupture and shear failure respectively [17]. 


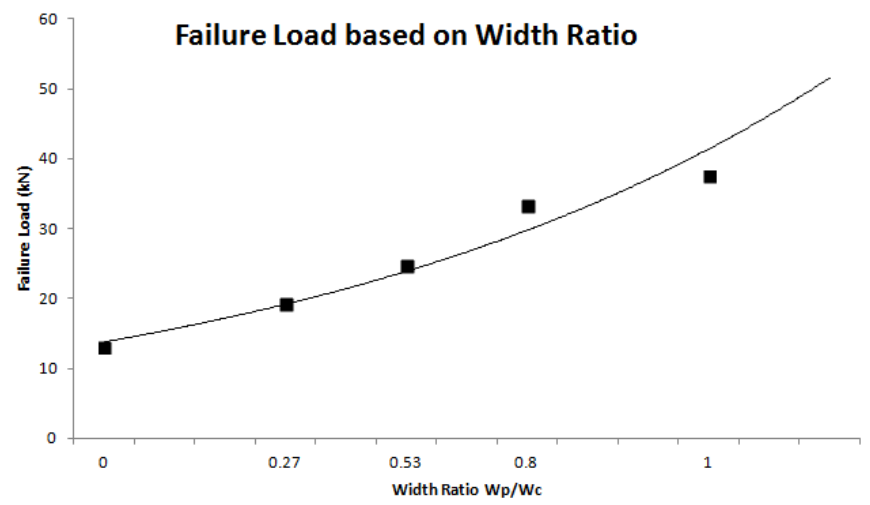

Fig. 4. Failure loads based on the different width ratios.

\subsection{Load versus deflection of concrete with various width ratios}

The graphs in Fig. 5 show load versus deflection for all the specimens with and without CFRP. It is clear from the figure that the CFRP does not only provide load enhancement but also improve the ductility of the specimen compared to the control specimens. In general, from the load versus deflection graph, it can be observed that an increasing CFRP width ratio leads to an improvement in the ultimate load as well as the stiffness of the strengthened CFRP specimens. This behaviour is noticeable at W75 (width ratio 1) compared to other width ratios and is consistent with the findings by [10].

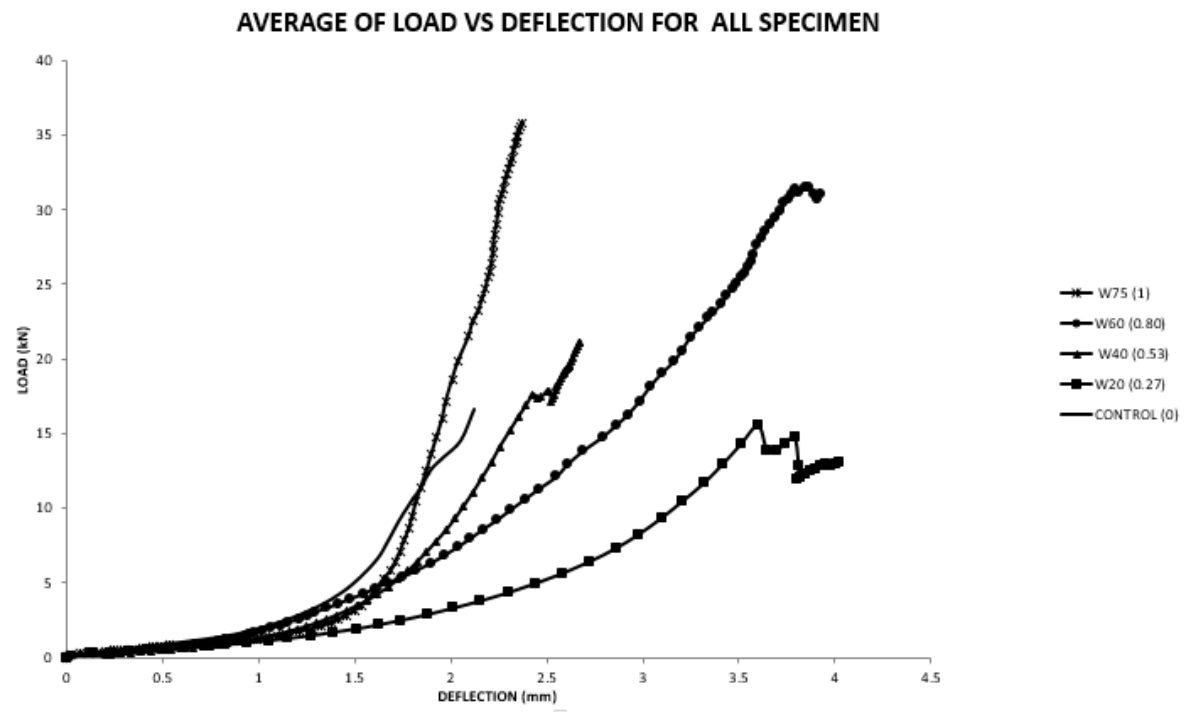

Fig. 5. Load versus deflection for all specimens. 


\subsection{Failure mode}

Table 2 shows the types of failure modes for each specimen with various width ratios. For a control specimen without CFRP, the failure mode is a typical flexural crack. For CFRP width ratios of 0.27 and 0.53 , both share a similar failure mode which is CFRP rupture.

Table 2. Types of failure mode for each specimen.

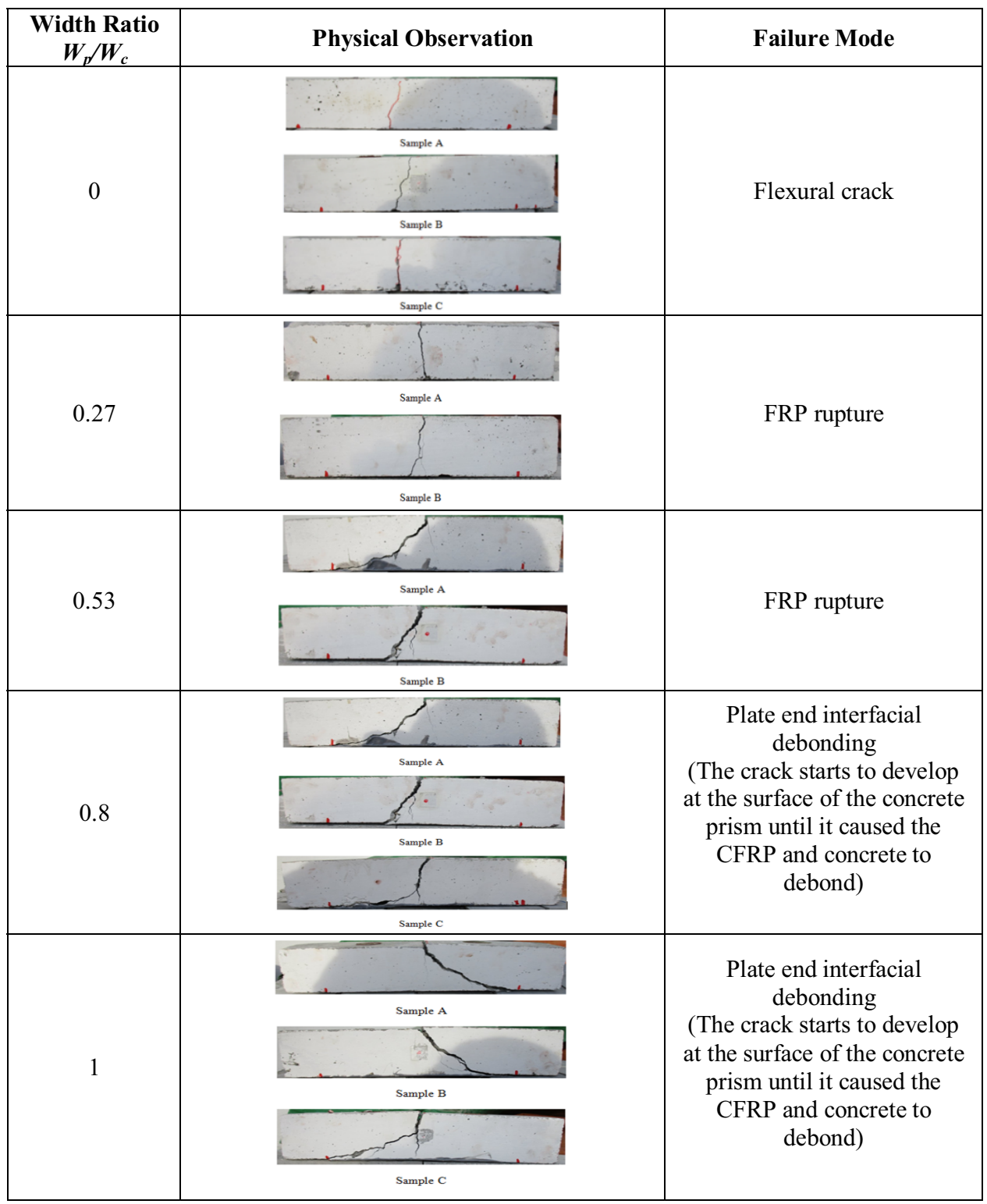

However, for the crack development of CFRP with a width ratio of 0.53 , the crack typically starts from the top and forms a shear crack before CFRP rupture. As the width ratio increases, the failure mode changes from CFRP rupture to plate end interfacial debonding with a thin concrete layer attached to the debonded CFRP sheet [11]. Although the failure 
mode of specimens attached to CFRP with width ratios of 0.8 and 1 was plate end interfacial debonding, it is proven that the ultimate load is higher as stated in this study (refer Table 1). Similar findings were also reported by Subramaniam et al. [13] indicating that the greater the CFRP width ratio, the higher the debonding strength of CFRP.

\section{Conclusion}

This is an experimental study on the effect of various CFRP bond widths on concrete prisms. All of the specimens were subjected to a three point load test to determine the ultimate load, deflection and failure mode of the CFRP strengthened concrete prism. It can be concluded that:

i) The ultimate load for CFRP strengthened concrete prisms increased as the CFRP width ratio increases.

ii) Significant load enhancement of more than $80 \%$ is achieved when the concrete is strengthened with a CFRP width ratio of 0.5 and above

iii) The increase in CFRP width ratio leads to an increase in the stiffness of the specimen hence resulting in a higher ultimate load.

iv) To avoid plate end debonding failure, it is recommended for future studies to provide an end anchor for the CFRP so that higher ultimate load and ductility can be achieved for the strengthened prisms.

This work was supported by the Jamilus Research Center, Faculty of Civil and Environmental Engineering, University Tun Hussein Onn Malaysia, Center for Graduate Studies, UTHM and the Research Acculturation Grant Scheme (RAGS) Vot. 053.

\section{References}

[1] C. Mikami, H.C. Wu and A. Elarbi, Effect of hot temperature on pull-off strength of FRP bonded concrete, Constr. Build. Mater., 91, 180-186 (2015)

[2] S.R. Abdullah, Fibre reinforced polymer rehabilitation of alkali aggregate reaction-damaged concrete structures, PhD Thesis, Monash University, Australia (2013)

[3] N. Ali, A.A.A. Samad, N. Mohamad and J. Jayaprakash, Shear behaviour of pre-cracked continuous beam repaired using externally bonded CFRP strips, Procedia Eng., 53, 129-144 (2013)

[4] D. De Domenico, P. Fuschi, S. Pardo and A.A. Pisano, Strengthening of steel-reinforced concrete structural elements by externally bonded FRP sheets and evaluation of their load carrying capacity, Compos. Struct., 118, 377-384 (2014)

[5] S. Shahidan, S. Salwa, M. Zuki, C.K. Keong and J. Jayaprakash, Repaired of fire-damaged concrete-filled double skin steel tubular (CFDST) columns with fiber reinforced polymer (FRP), ARPN J. Eng. Appl. Sci., 11(6), 3718-3725, (2016)

[6] S. Shahidan, S.S.M. Zuki and N. Jamaluddin, Damage grading system for severity assessment on concrete structure, Case Stud. Constr. Mater., 5, 79-86 (2016)

[7] S. Ma, N. M. Bunnori and K.K. Choong, Behavior of reinforced concrete box beam strengthened with CFRP U-wrap strips under torsion, MATEC Web of Conferences, 47, 02002 (2016)

[8] E. Choi, B.S. Cho, J.S. Jeon and S.J. Yoon, Bond behavior of steel deformed bars embedded in concrete confined by FRP wire jackets, Constr. Build. Mater., 68, 716-725 (2014)

[9] M. Batikha and F. Alkam, The effect of mechanical properties of masonry on the behavior of FRP-strengthened masonry-infilled RC frame under cyclic load, Compos. Struct., 134, 513-522 (2015)

[10]H. Mazaheripour and J.A.O. Barros, Tension-stiffening model for FRC reinforced by hybrid FRP and steel bars, 88, 162-181 (2016)

[11]U.S. Camli and B. Binici, Strength of carbon fiber reinforced polymers bonded to concrete and masonry, Constr. Build. Mater., 21(7), 1431-46 (2007) 
[12] L. De Lorenzis, B. Miller and A. Nanni, Bond of fiber-reinforced polymer laminates to concrete, ACI Mater. J., 98(3), 256-264 (2001)

[13] K.V. Subramaniam, C. Carloni and L. Nobile, Width effect in the interface fracture during shear debonding of FRP sheets from concrete, Eng. Fract. Mech., 74(4), 578-594 (2007)

[14] S.K. Woo and Y. Lee, Experimental study on interfacial behavior of CFRP bonded concrete, KSCE J. Civ. Eng., 14(3), 385-93 (2010)

[15]T. Xu, Z.J. He, C.A. Tang, W.C. Zhu and P.G. Ranjith, Finite element analysis of width effect in interface debonding of FRP plate bonded to concrete, Finite Elem. Anal. Des., 93(C), 30-41 (2015)

[16]N. Moshiri, A. Hosseini and D. Mostofinejad, Strengthening of RC columns by longitudinal technique, Constr. Build. Mater., 79, 318-325 (2015)

[17]A. Napoli, G. de Felice, S. De Santis and R. Realfonzo, Bond behaviour of steel reinforced polymer strengthening systems, Compos. Struct., 152, 499-515 (2016) 